\title{
Gestão da retenção de alunos em cursos on-line sob a perspectiva da aceitação da tecnologia
}

\author{
Vanessa Edy Dagnoni Mondini' \\ Maria José Carvalho de Souza Domingues"
}

RESUMO

A retenção em cursos on-line é reconhecidamente baixa. Neste texto objetiva-se avaliar a relação entre fatores de aceitação da tecnologia e a retenção de alunos nesta modalidade, tendo, para o efeito, sido usados a Teoria Unificada de Aceitação e Uso de Tecnologia (UTAUT) e o Modelo de Fatores de Sucesso de Sistemas de Informação de DeLone e McLean (D\&M). A pesquisa é descritiva, com abordagem quantitativa e análise pela técnica de modelagem de equações estruturais. Foram desenvolvidas seis hipóteses relacionando fatores tecnológicos à retenção e investigados alunos de cursos livres de contabilidade. Os resultados indicam que a relação entre a qualidade da informação e a retenção é a mais relevante entre as pesquisadas, seguida pela motivação hedônica e pela autoeficácia. Os achados contribuem para o entendimento dos gestores de que a retenção pode ser obtida especialmente a partir de investimentos na qualidade dos conteúdos disponibilizados, em sistemas com ambientes agradáveis e prazerosos de serem utilizados e em capacitações que tornem os usuários confiantes para o uso do sistema.

PALAVRAS-CHAVE

gestão de cursos on-line; retenção de alunos; aceitação da tecnologia.

Instituto Federal de Santa Catarina, Gaspar, SC, Brasil.

"Fundação Universidade Regional de Blumenau, Blumenau, SC, Brasil. 


\title{
STUDENT RETENTION MANAGEMENT IN ONLINE COURSES UNDER THE PERSPECTIVE OF THE ACCEPTANCE OF TECHNOLOGY
}

\begin{abstract}
Student retention rates in online courses are admittedly low. This article aims to evaluate the relationship between factors of acceptance of technology and the retention of students in online courses. The UTAUT Theory and the DeLone McLean Model serve as a basis for the study. The research is descriptive, with quantitative approach and analysis by the modeling technique of structural equations. Six hypotheses were developed relating technological factors to retention and students of free accounting courses were investigated. The results indicate that the relationship between information quality and retention is the most relevant among those surveyed, followed by hedonic motivation and self-efficacy. These findings contribute to the understanding of managers that retention can be obtained especially from investments in the quality of content, systems with agreeable and pleasant environments of use and capabilities that make users confident in using the system.
\end{abstract}

\section{KEYWORDS}

management of online courses; retention of students; acceptance of technology.

\section{GESTIÓN DE LA RETENCIÓN DE ALUMNOS EN CURSOS ONLINE BAJO LA PERSPECTIVA DE LA ACEPTACIÓN DE LA TECNOLOGÍA}

\section{RESUMEN}

Las tasas de retención de alumnos en cursos en línea son reconocidamente bajas. En esto artículo, se pretende evaluar la relación entre factores de aceptación de la tecnología y la retención de alumnos en esta modalidad. La Teoría UTAUT y el Modelo de Factores de éxito de Sistemas de Información de DeLone y McLean (D\&M) sirvieron de base para la investigación. La investigación es descriptiva, con abordaje cuantitativo y análisis por la técnica de modelado de ecuaciones estructurales. Se desarrollaron seis hipótesis relacionando factores tecnológicos a la retención e investigados alumnos de cursos libres de contabilidad. Los resultados indican que la relación entre la calidad de la información y la retención es la más relevante entre las investigadas, seguida por la motivación hedónica y la autoeficacia. Los hallazgos contribuyen al entendimiento de los gestores de que la retención puede ser obtenida especialmente a partir de inversiones en la calidad de los contenidos ofrecidos, en sistemas con ambientes agradables y placenteros de ser utilizados y en capacitaciones que hagan a los usuarios confiados para el uso del sistema.

\section{PALABRAS CLAVE}

gestión de cursos en línea; retención de alumnos; aceptación de la tecnología. 


\section{INTRODUÇÃO}

Apesar da ascensão da modalidade de cursos on-line (ABED, 2016), fatores críticos relacionados à inadequação dos sistemas tecnológicos e à insatisfação dos usuários com a tecnologia (Lee, 2010) têm levado as instituições de ensino a arcarem com altos custos e a enfrentarem dificuldades na aceitação de seus cursos (Martín García, Dujo e Rodríguez, 2014; Sharma, Joshi e Sharma, 2016).

Em função da ausência da presencialidade em cursos on-line, pesquisas sobre retenção enfatizam a relevância das tecnologias da informação e comunicação (TICs). Atitudes e comportamentos positivos dos alunos com relação às tecnologias e aos recursos dos ambientes de aprendizagem são fatores explicativos da permanência nos cursos (Laguardia e Portela, 2009).

Entre as teorias relacionadas à aceitação da tecnologia, a Teoria Unificada de Aceitação e Uso de Tecnologia (UTAUT) e o Modelo de Fatores de Sucesso de Sistemas de Informação de DeLone e McLean (D\&M) são amplamente utilizados em pesquisas sobre adoção e uso da tecnologia da informação (Venkatesh, Zhang e Sykes, 2011; Williams et al., 2011; Ifinedo, 2012; Dečman, 2015).

As teorias mencionadas contemplam uma série de aspectos importantes a respeito da aceitação da tecnologia. Enquanto o modelo proposto pela UTAUT se concentra em critérios comportamentais, como expectativa de desempenho, expectativa de esforço, motivação hedônica e autoeficácia (Venkatesh et al.,2003; Venkatesh, Thong e Xu, 2012), o Modelo de Fatores de Sucesso de Sistemas de Informação de DeLone e McLean (D\&M) enfoca fatores técnicos, como a qualidade da informação e a qualidade do sistema (Delone e McLean, 1992). No entanto, ao serem utilizados separadamente - fatores comportamentais, na UTAUT, e técnicos, no Modelo de Fatores de Sucesso de Sistemas de Informação de DeLone e McLean $(\mathrm{D} \& \mathrm{M})$-, são desconsideradas possibilidades potencialmente importantes que poderiam ser obtidas pela integração total ou parcial desses fatores.

Por essa perspectiva, objetiva-se avaliar, com foco na gestão, a relação entre os fatores de aceitação da tecnologia, comportamentais e técnicos, e a retenção de alunos em cursos on-line.

Propõe-se a existência de relação positiva entre os fatores comportamentais e técnicos de aceitação da tecnologia e a retenção de alunos em cursos on-line. A retenção é mensurada pela intenção do aluno de continuar o curso on-line e está associada à aceitação do sistema tecnológico utilizado pelo aluno para realizar o curso, como verificado nos trabalhos de Chiu et al. (2005), Chiu e Wang (2008), Roca e Gagné (2008) e Lin (2011).

Propostas que buscaram a integração de teorias de aceitação da tecnologia já foram realizadas anteriormente (Alshehri et al., 2012; Motaghian, Hassanzadeh e Moghadam,2013; Osubor e Chiemeke, 2015; Mohammadi, 2015). No entanto, não envolveram o conjunto de fatores escolhidos neste trabalho, nem os estudaram sob a perspectiva da gestão universitária relacionada à retenção de alunos em cursos on-line.

Há escassez de estudos que analisam o problema da baixa retenção de alunos, sob a perspectiva da gestão. A maioria se concentra em questões pedagógicas e adaptação dos alunos aos processos de ensino e aprendizagem, ignorando o processo de gestão que permeia a construção do processo educacional (Hora, 1994; Schlemmer, 
Saccol e Garrido, 2007; Castro e Ladeira, 2010; Sá e Padilha, 2013; Daudt e Behar, 2013). Assim, ao buscar resultados que favoreçam as tomadas de decisão dos gestores a respeito de investimentos e intervenções necessárias para promover a permanência dos alunos nos cursos, busca-se contribuir para uma perspectiva teórica mais voltada à gestão universitária, com ênfase em cursos na modalidade on-line.

\section{BASE TEÓRICA}

\section{RETENÇÃO EM CURSOS ON-LINE}

Apesar de vantagens como economia de escala e ampliação do mercado de atuação, oferecer cursos on-line traz desafios às instituições, como o baixo índice de retenção (continuidade dos alunos no curso até a conclusão) (Allen e Seaman, 2007; Levy, 2007; Patterson e McFadden, 2009; ABED, 2016).

Mesmo que favorecidos pela ascensão das TICs, os cursos on-line, quando comparados aos presenciais, apresentam uma taxa de conclusão $20 \%$ menor. A descontinuidade nos estudos atinge, no Brasil, uma taxa média de até $25 \%$ de evasão nas diferentes modalidades a distância e $40 \%$ nas instituições que oferecem cursos totalmente on-line (ABED, 2016). Características como flexibilidade de local e tempo, interatividade, possibilidade de avaliação on-line e feedback imediato levam os alunos a se inscreverem nos cursos, mas não a permanecer neles (Fozdar e Kumar, 2007; Njenga e Fourie, 2010; Joo, Joung e Sim, 2011; Lee e Choi, 2013).

A baixa retenção implica no insucesso do projeto, no não recebimento de subsídios de agências de fomento, além de custos não financeiros, como repercussões negativas na reputação acadêmica da instituição de ensino superior (IES) e desprestígio da modalidade como uma alternativa de ensino de qualidade (Laguardia e Portela, 2009).

O foco das pesquisas sobre evasão, anteriormente concentrado nos motivos pelos quais os estudantes desistiam dos cursos, passou a centrar-se na retenção, atribuindo aos gestores das instituições de ensino a responsabilidade por ações de permanência e êxito dos alunos (Freitas, 2009). Por essa perspectiva, a retenção implica na capacidade institucional de formar com sucesso os estudantes que nela se matriculam (Berger e Lyon, 2005).

\section{ACEITAÇÃO DA TECNOLOGIA}

Entre as diversas concepções teóricas, este estudo aborda o uso da tecnologia pela perspectiva intenção/comportamento em nível individual (em que a intenção comportamental dos usuários é utilizada como variável dependente), originada da Teoria da Ação Racionalizada, de Fishbein e Ajzen (1975).

Em especial, foram utilizados, como base, a UTAUT, de Venkatesh et al. (2003), e o Modelo de Fatores de Sucesso de Sistemas de Informação de DeLone e McLean (D\&M) (DeLone e McLean, 2003), ambos pertencentes aos quadros teóricos que explicam a aceitação e o uso da tecnologia (Premkumar e Bhattacherjee, 2008; Mohamadali e Garibaldi, 2010).

O modelo proposto pela UTAUT (Figura 1) se concentra em critérios comportamentais (Venkatesh et al., 2003). 
Já o Modelo de Fatores de Sucesso de Sistemas de Informação de DeLone e McLean (D\&M) (Figura 2), por sua vez, privilegia fatores técnicos, como a qualidade da informação e a qualidade do sistema (Delone e McLean, 1992).

A intenção dos usuários em continuar a usar a tecnologia do curso é considerada um dos principais determinantes do sucesso da modalidade on-line (King e He, 2006; Mohammadi, 2015). Compreender os fatores que influenciam essa intenção é uma questão crítica para pesquisadores e profissionais da área (Chiu et al., 2005; Roca, Chiu e Martínez, 2006; King e He, 2006; Mohammadi, 2015).

A partir das abordagens teóricas UTAUT, de Venkatesh et al. (2003), UTAUT2, de Venkatesh, Thong e Xu (2012), Modelo de Fatores de Sucesso de Sistemas de Informação de DeLone e McLean (D\&M) (DeLone e McLean, 2003), e das evidências levantadas na revisão da literatura, estabeleceram-se duas hipóteses gerais:

- H1 - há uma relação positiva entre fatores comportamentais de aceitação da tecnologia e a retenção de alunos em cursos on-line;

- H2 - bá uma relação positiva entre fatores técnicos de aceitação da tecnologia $e$ a retenção de alunos em cursos on-line.

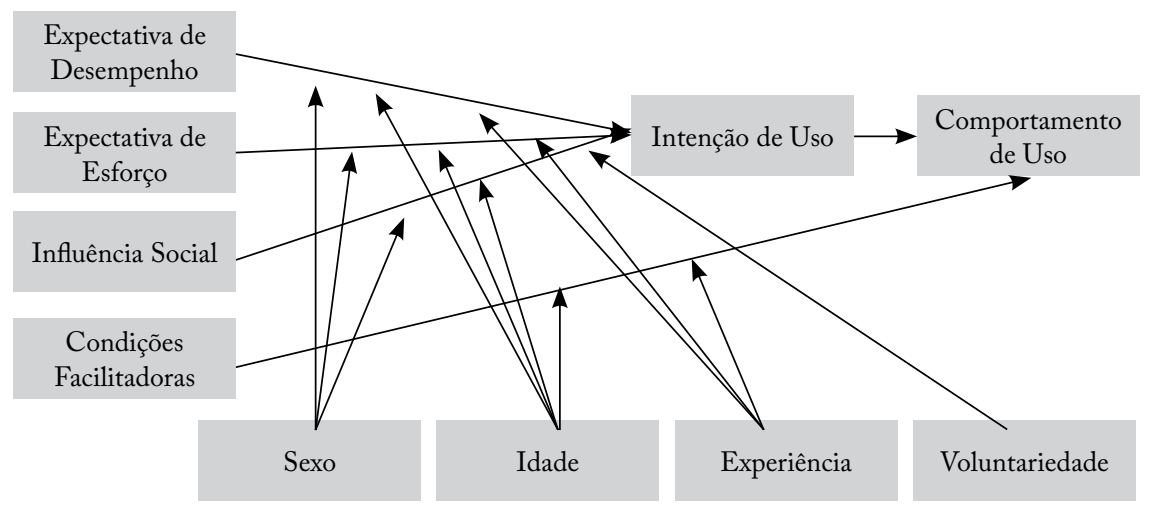

Figura 1 - Teoria Unificada de Aceitação e Uso de Tecnologia.

Fonte: adaptado de Venkatesh et al. (2003).

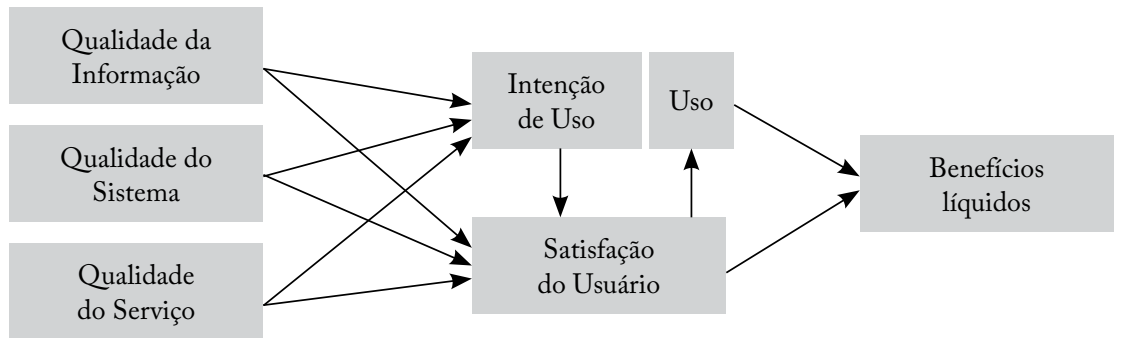

Figura 2 - Modelo de Fatores de Sucesso de Sistemas de Informação de DeLone e McLean (D\&M).

Fonte: adaptado de Delone e McLean (2003). 
Essas duas hipóteses gerais foram divididas em seis específicas, quatro delas referentes a fatores comportamentais e duas, a fatores técnicos (Figura 3).

Entre as hipóteses comportamentais, apresenta-se a primeira: $H 1 a-b a ́ a$ uma relação positiva entre a expectativa de desempenho e a retenção de alunos em cursos on-line. As variáveis de motivação extrínseca são voltadas à melhoria no desempenho, à rapidez no entendimento do conteúdo, à utilidade do sistema e ao aumento de produtividade. Há um cálculo racional entre a decisão de permanecer na atividade e os benefícios a serem conquistados a partir do seu uso (Taylor e Todd, 1995; Venkatesh e Davis, 1996, 2000; Venkatesh, 2000; Gupta, Dasgupta e Gupta, 2008). A expectativa de desempenho é um dos mais fortes determinantes da atitude do estudante de permanecer no curso (Arbaugh, 2005; Akbar, 2013; Nguyen, Nguyen e Cao, 2014).

A segunda hipótese comportamental, H1b — bá uma relação positiva entre a expectativa de esforço e a retenção de alunos em cursos on-line, está ancorada na relação entre as variáveis voltadas à facilidade de uso do sistema e a intenção do indivíduo de permanecer no curso. Tecnologias mais fáceis de usar são menos ameaçadoras para o indivíduo, levando a uma maior interação entre o sujeito e a tecnologia (Venkatesh e Davis, 1996, 2000; Venkatesh, 2000; Ong, Lai e Wang, 2004). A facilidade de uso do sistema é especialmente importante para a permanência do aluno no curso, já que as interações face a face com o professor são ausentes (Joo, Joung e Kim, 2013; Dečman, 2015; Mikalef, Pappas e Giannakos, 2016).

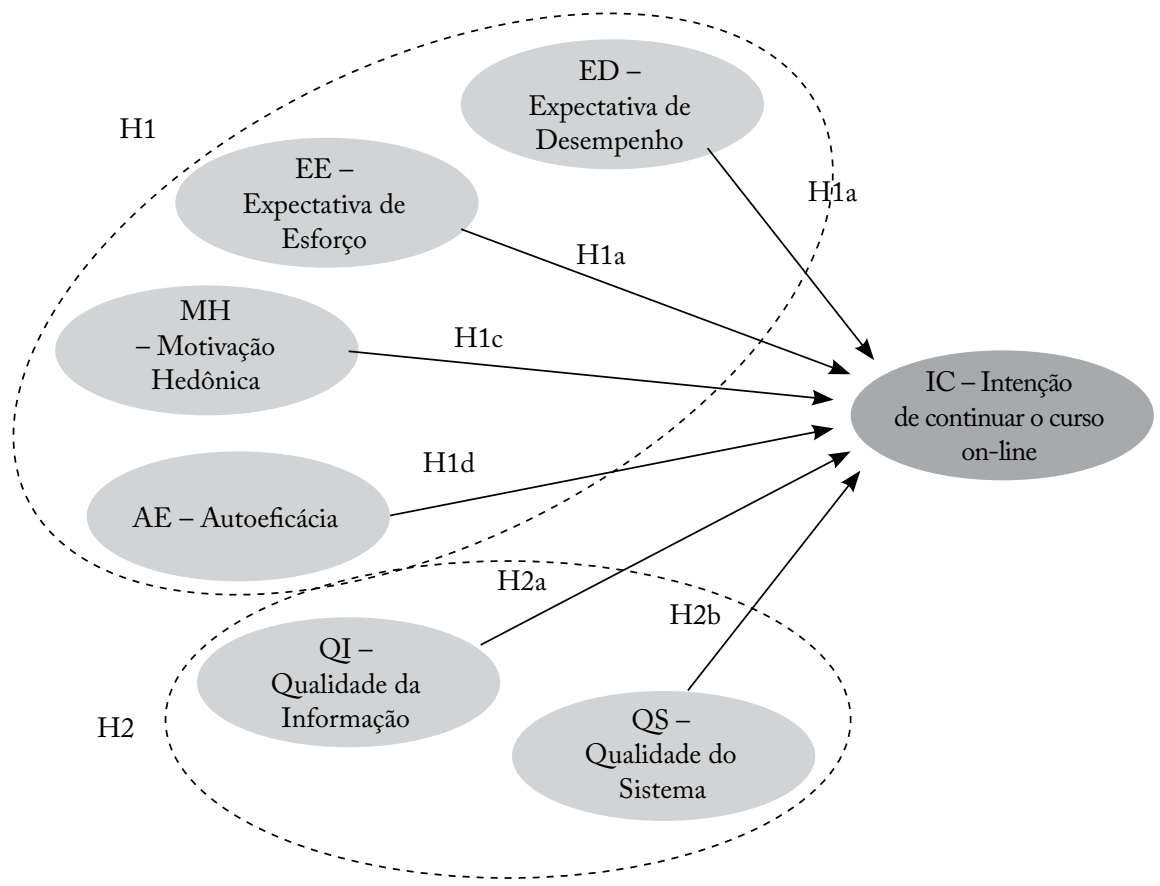

Figura 3 - Modelo teórico e hipóteses propostas.

Fonte: elaboração própria. 
A terceira hipótese comportamental, $H 1 c$ — há uma relação positiva entre a motivação hedônica e a retenção de alunos em cursos on-line, está fundamentada nas evidências da influência de variáveis de motivação intrínsecas, como prazer, diversão e interesse, sobre a intenção do aluno de continuar o curso que está realizando. Motivadores hedônicos, como prazer, diversão, brincadeiras e felicidade, podem se sobressair às motivações utilitárias, atribuindo um significado subjetivo que complementa os atributos concretos, voltando-se para construções imaginativas da realidade (Hill e Gardner, 1987). A inclusão de conteúdos com imagens animadas, foco em cores, sons e layouts esteticamente atraentes, é importante para incentivar o uso prolongado do sistema (van der Heijden, 2004).

A quarta hipótese comportamental, H1d - há uma relação positiva entre a autoeficácia e a retenção de alunos em cursos on-line, toma por base as evidências da influência das variáveis relacionadas à autoavaliação do aluno sobre sua capacidade de executar certas atividades a fim de atingir um grau de performance e sobre sua intenção de continuar o curso on-line. Crenças individuais, confiança e expectativas sobre a própria capacidade de executar uma tarefa levam à decisão de permanecer na atividade que está sendo realizada (Bandura, 1986; Venkatesh et al., 2003). Entre as explicações possíveis para as interrupções nos cursos, está a falta de autoconfiança no uso do sistema (Tsai et al., 2011), o que leva a baixas aspirações e à redução dos esforços para permanecer na atividade em realização (Bandura, 1986).

A primeira hipótese técnica, $\mathrm{H} 2 \mathrm{a}$ - bá uma relação positiva entre a qualidade da informação e a retenção de alunos em cursos on-line, fundamenta-se nas evidências da influência das variáveis, como atualidade, relevância, exatidão, compreensibilidade, integralidade, valor, dinamismo, personalização e variedade das informações geradas por um sistema de informação, e tem provado ser fortemente associada ao uso do sistema do curso (Delone e McLean, 2003). A qualidade da informação é frequentemente vista como um antecedente fundamental para a intenção de utilizar o sistema do curso on-line (Cheng, 2012; Ramayah, Ahmad e Lo, 2010; Wang e Chiu, 2011).

A segunda hipótese técnica, $H 2 b$ - Há uma relação positiva entre a qualidade do sistema e a retenção de alunos em cursos online, está ancorada nas evidências da influência de variáveis relacionadas à funcionalidade, confiabilidade, flexibilidade, portabilidade e integrabilidade do sistema sobre a intenção do aluno de permanecer no curso on-line (Delone e McLean, 2003; Urbach, Smolnik e Riempp, 2010). Plataformas de software baseadas em uma variedade de meios de comunicação claros e eficientes, que facilitem a interação entre os participantes e a instituição, estão positivamente associadas à permanência nos cursos baseados na web (Arbaugh, 2005).

Propostas de integração de teorias diferentes, conforme Wixom e Todd (2005), podem e devem ser realizadas a fim de se ampliar a compreensão sobre os aspectos relacionados ao uso da tecnologia.

\section{MÉTODO E PROCEDIMENTOS DE PESQUISA}

A pesquisa caracteriza-se como descritiva e quantitativa, com utilização de uma abordagem hipotético-dedutiva por meio de dados primários. A população da pesquisa é representada por 830 alunos de cursos livres, oferecidos de forma on-line por uma 
IES privada, referência na oferta de cursos na área contábil (conceito institucional 5 pelo MEC). A amostra, obtida por acessibilidade, foi composta pelos 147 respondentes e atendeu ao valor sugerido por Ringle, Silva e Bido (2014) no teste G*Power.

Realizou-se a coleta de dados entre as datas de 22 de março e 22 de junho de 2016. Nesse período, enviou-se o link do questionário disponibilizado no Google Docs três vezes aos matriculados. Os dados foram analisados seguindo três etapas indicadas por Ringle, Silva e Bido (2014): Estatística Descritiva, Análise Fatorial Confirmatória e Modelagem de Equações Estruturais (MEE) com Mínimos Quadrados Parciais (PLS).

O desenvolvimento das escalas para mensurar cada construto pode ser observado no Quadro 1.

Dividiu-se o questionário em duas partes. A primeira foi composta por dados demográficos (sexo, idade, escolaridade, curso que realiza e experiência anterior em cursos on-line).

A segunda parte foi formada por 36 questões que representam os 7 construtos pesquisados. Essas questões foram concebidas originalmente na língua inglesa. No entanto, vários pesquisadores brasileiros, como Frezatti, Aguiar e Rezende (2008), Albertin e Brauer (2012) e Duarte, Vieira e Silva (2015), já as traduziram para o português e as adaptaram ao contexto educacional. Apesar dessa validação, optou-se por sujeitar os questionários originais em língua inglesa, novamente a dois especialistas da língua inglesa, para a validade de conteúdo. Dessa maneira, procurou-se assegurar, a partir da tradução e tradução reversa, a preservação das equivalências semântica, idiomática, cultural e conceitual das escalas (Reichenheim e Moraes, 2007).

\section{APRESENTAÇÃO E ANÁLISE DOS RESULTADOS}

A amostra foi composta por 147 estudantes de cursos de curta duração relacionados à área contábil, predominantemente do sexo masculino (67\%), com faixa etária concentrada entre 31 e 45 anos (60\%). A maioria tem especialização como grau de escolaridade (55,1\%), e $68,72 \%$ já haviam concluído ao menos dois cursos on-line antes desse que estavam realizando no momento da coleta de dados.

O perfil sugere que a amostra estudada é composta por indivíduos mais velhos, com nível educacional elevado e experiência em cursos on-line. Tais características indicam certa qualificação da amostra em termos de experiência e nível educacional, permitindo inferir que esse grupo está acostumado à modalidade on-line e preparado para a utilização das diferentes ferramentas tecnológicas dos sistemas dos cursos.

A análise descritiva dos construtos apontou, como mais alta, a média da variável dependente intenção de continuar o curso on-line $(5,93)$, evidenciando o desejo dos alunos de continuar realizando os cursos. Todos os construtos obtiveram médias altas: expectativa de esforço $(5,72)$, autoeficácia $(5,68)$, qualidade da informação $(5,61)$, qualidade do sistema $(5,59)$, expectativa de desempenho $(5,58)$ e motivação hedônica $(4,92)$. Isso indica um nível alto de concordância dos alunos de que o uso do sistema do curso lhes traz melhor desempenho nas atividades de 


\section{Quadro 1 - Caracterização do instrumento de coleta de dados.}

\begin{tabular}{|c|c|}
\hline \multicolumn{2}{|c|}{ Fatores Comportamentais (UTAUT) } \\
\hline Expectativa de Desempenho & Adaptado de Venkatesh et al. (2003) \\
\hline \multicolumn{2}{|c|}{ Usar o sistema do curso on-line melhora meu desempenho nas minhas atividades de aprendizagem. } \\
\hline \multicolumn{2}{|c|}{ Usar o sistema do curso on-line me ajuda a entender as coisas mais rapidamente. } \\
\hline \multicolumn{2}{|c|}{ Considero o sistema do curso on-line útil para as minhas atividades de aprendizagem. } \\
\hline \multicolumn{2}{|c|}{ Usar o sistema do curso on-line em minhas atividades de aprendizagem aumenta a minha produtividade. } \\
\hline Expectativa de Esforço & Adaptado de Venkatesh et al. (2003) \\
\hline \multicolumn{2}{|c|}{ É fácil se acostumar a usar o sistema do curso on-line. } \\
\hline \multicolumn{2}{|c|}{ Minha interação com o sistema do curso on-line é clara e de fácil compreensão. } \\
\hline \multicolumn{2}{|c|}{ É fácil fazer com que o sistema do curso on-line atenda aos meus comandos. } \\
\hline \multicolumn{2}{|c|}{ Considero o sistema do curso on-line fácil de usar. } \\
\hline Motivação Hedônica & $\begin{array}{l}\text { Adaptado de Venkatesh et al. (2003) e } \\
\text { Bernardo, Marimon e Alonso-Almeida (2012) }\end{array}$ \\
\hline \multicolumn{2}{|c|}{ Usar o sistema do curso on-line é divertido. } \\
\hline \multicolumn{2}{|c|}{ Usar o sistema do curso on-line é agradável. } \\
\hline \multicolumn{2}{|c|}{ Usar o sistema do curso on-line é interessante. } \\
\hline \multicolumn{2}{|c|}{ Usar o sistema do curso on-line é prazeroso. } \\
\hline \multicolumn{2}{|c|}{ Quando interajo com o sistema de curso on-line, nem sinto o tempo passar. } \\
\hline Autoeficácia & Adaptado de Roca, Chiu e Martínez (2006) \\
\hline \multicolumn{2}{|c|}{ Confio na minha capacidade de navegar seguindo os ícones do sistema do curso on-line. } \\
\hline \multicolumn{2}{|c|}{ Confio na minha capacidade de procurar informações nos links do sistema do curso on-line. } \\
\hline \multicolumn{2}{|c|}{ Confio na minha capacidade de acessar a(s) aula(s) virtual(s) disponível(s) no sistema do curso on-line. } \\
\hline \multicolumn{2}{|c|}{ Confio na minha capacidade de acessar os slides do videoaulas disponíveis no sistema do curso on-line. } \\
\hline \multicolumn{2}{|c|}{ Confio na minha capacidade de acessar e participar dos quizzes disponíveis no sistema do curso on-line. } \\
\hline \multicolumn{2}{|c|}{ Confio na minha capacidade de acessar a(s) prova(s) on-line disponível(s) no sistema do curso on-line. } \\
\hline Intenção de Continuar & $\begin{array}{c}\text { Adaptado de Venkatesh et al. (2003) e Lin e } \\
\text { Wang (2012) }\end{array}$ \\
\hline \multicolumn{2}{|c|}{ Recomendarei a outras pessoas que façam este curso on-line. } \\
\hline \multicolumn{2}{|c|}{ No geral, pretendo continuar usando os cursos on-line desta instituição. } \\
\hline \multicolumn{2}{|c|}{ Concluir este curso on-line é importante para mim. } \\
\hline \multicolumn{2}{|c|}{ Vou terminar este curso on-line independente das dificuldades que eu possa ter. } \\
\hline \multicolumn{2}{|c|}{ Certamente me matricularei para outra fase deste curso on-line, se houver. } \\
\hline \multicolumn{2}{|c|}{ Fatores Técnicos (D\&M) } \\
\hline Qualidade da Informação & Adaptado de DeLone e McLean (2003) \\
\hline \multicolumn{2}{|c|}{ As informações contidas no sistema do curso on-line são exatas e livres de erros. } \\
\hline As informações contidas no & são confiáveis em termos de fonte e conteúdo. \\
\hline
\end{tabular}




\section{Quadro 1 - Continuação.}

\begin{tabular}{|c|c|}
\hline Fatores Técnicos & \\
\hline As informações cont & o relevantes para a minha aprendizagem. \\
\hline As informações cont & o suficientes para a minha aprendizagem. \\
\hline As informações cont & o de fácil entendimento. \\
\hline As informações cont & o atualizadas. \\
\hline Qualidade do Sistema & Adaptado de DeLone e McLean (2003) \\
\hline O sistema do curso or & s ícones seguem uma lógica simples e intuitiva). \\
\hline O sistema do curso or & $\mathrm{m}$ a encontrar as informações de que eu preciso. \\
\hline As páginas e as func & -line carregam rapidamente. \\
\hline O sistema do curso o & \\
\hline $\begin{array}{l}\text { Considero as ferram } \\
\text { do curso on-line, ade }\end{array}$ & (quizzes, videoaulas, provas etc.) do sistema \\
\hline $\begin{array}{l}\text { O sistema do curso } \\
\text { minha aprendizager }\end{array}$ & ção e comunicação que colaboram para \\
\hline O sistema do curso or & s ícones seguem uma lógica simples e intuitiva). \\
\hline $\begin{array}{l}{ }^{*} \text { Todas as questões } f \\
1-\text { Discordo Totaln }\end{array}$ & t de 7 pontos \\
\hline
\end{tabular}

Fonte: elaboração própria.

aprendizagem, que o sistema é fácil de usar, que se sentem confiantes na utilização das ferramentas do sistema, que as informações são relevantes, confiáveis, exatas e livres de erros, bem como que o sistema carrega rapidamente e possui ferramentas que favorecem a aprendizagem.

A análise fatorial confirmatória indicou que todas as questões obtiveram cargas dentro dos parâmetros ideais: carga padronizada acima de 0,7 (automaticamente, $R^{2}$ acima de 0,5 ), teste $t \geq 1,96$, permitindo que sejam mantidas (Hair Junior et al., 2014) (Tabela 1).

Em todas as dimensões, o alfa de Cronbach se mostrou superior a 0,70, e a confiabilidade composta, acima de 0,90 (Hair Junior et al., 2014), sugerindo que as respostas em seu conjunto são confiáveis. Os valores da variância média extraída (average variance extracted - AVE) estão acima de 0,50, indicando que as variáveis se correlacionam positivamente com os seus respectivos construtos (Fornell e Larcker, 1981) (Tabela 2).

A raiz quadrada da AVE de cada construto deve exceder o maior valor das correlações dos demais construtos (Hair Junior et al., 2014). Ao analisar os construtos de forma conjunta, observa-se que não existe validade discriminante entre Qualidade da Informação (QI) e Qualidade do Sistema (QS), indicando a necessidade de se excluir um ou outro (Tabela 3 ).

O construto QS apresentou nível superior a 5, indicando colinearidade e a necessidade de sua exclusão (Hair Junior et al., 2014). 
A partir da exclusão do construto QS, a raiz quadrada da AVE, de acordo com a Tabela 4, mostrou-se superior em todas as correlações entre as dimensões, conferindo validade discriminante e indicando que há adequação do modelo em relação às variáveis estudadas (Hair Junior et al., 2014).

A Tabela 5 indica que todos os valores ficaram abaixo de 5, conforme recomendado por Hair Junior et al. (2014).

A Figura 4, apresenta a modelagem final do estudo proposto.

A variância explicada foi de 0,70 , indicando que os fatores qualidade da informação $(0,346)$, motivação hedônica $(0,233)$ e autoeficácia $(0,197)$ foram responsáveis por $70 \%$ da variação na intenção comportamental dos alunos de continuar o curso on-line. Esse valor, para a área de ciências sociais aplicadas, é considerado

Tabela 1 - Avaliação do modelo de mensuração: confiabilidade.

\begin{tabular}{l|c|c|c}
\hline Dimensão & AVE & Alfa de Cronbach & $\begin{array}{c}\text { Confiabilidade } \\
\text { Composta }\end{array}$ \\
\hline $\mathrm{AE}$ & 0,769 & 0,940 & 0,952 \\
\hline $\mathrm{ED}$ & 0,814 & 0,924 & 0,946 \\
\hline $\mathrm{EE}$ & 0,831 & 0,932 & 0,952 \\
\hline $\mathrm{IC}$ & 0,746 & 0,915 & 0,936 \\
\hline $\mathrm{MH}$ & 0,797 & 0,936 & 0,951 \\
\hline $\mathrm{QI}$ & 0,693 & 0,910 & 0,931 \\
\hline $\mathrm{QS}$ & 0,753 & 0,934 & 0,948 \\
\hline
\end{tabular}

Fonte: dados da pesquisa.

AVE: Average Variance Extracted (variância média extraída); AE: Autoeficácia; ED: Expectativa de Desempenho; EE: Expectativa de Esforço; IC: Intenção de Continuar; MH: Motivação Hedônica; QI: Qualidade da Informação; QS: Qualidade do Sistema.

Tabela 2 - Validade Discriminante no nível dos construtos (variáveis latentes).

\begin{tabular}{l|c|c|c|c|c|c|c}
\hline \multicolumn{7}{c}{ Validade Discriminante } \\
\hline & AE & ED & EE & IC & MH & Ol & OS \\
\hline AE & 0,877 & & & & & & \\
\hline $\mathrm{ED}$ & 0,637 & 0,902 & & & & & \\
\hline $\mathrm{EE}$ & 0,640 & 0,687 & 0,912 & & & & \\
\hline $\mathrm{IC}$ & 0,686 & 0,745 & 0,632 & 0,864 & & & \\
\hline $\mathrm{MH}$ & 0,616 & 0,744 & 0,772 & 0,710 & 0,893 & & \\
\hline $\mathrm{QI}$ & 0,673 & 0,755 & 0,614 & 0,767 & 0,647 & 0,833 & \\
\hline QS & 0,713 & 0,762 & 0,729 & 0,778 & 0,734 & 0,879 & 0,868 \\
\hline
\end{tabular}

Fonte: dados da pesquisa.

AE: Autoeficácia; ED: Expectativa de Desempenho; EE: Expectativa de Esforço; IC: Intenção de Continuar; MH: Motivação Hedônica; QI: Qualidade da Informação; QS: Qualidade do Sistema. 
Tabela 3 - Diagnóstico de colinearidade.

\begin{tabular}{l|c}
\hline Dimensão & VIF \\
\hline $\mathrm{AE}$ & 2,256 \\
\hline $\mathrm{ED}$ & 3,270 \\
\hline $\mathrm{EE}$ & 3,075 \\
\hline $\mathrm{IC}$ & - \\
\hline $\mathrm{MH}$ & 3,299 \\
\hline $\mathrm{QI}$ & 4,998 \\
\hline $\mathrm{QS}$ & $\mathbf{6 , 3 2 9}$ \\
\hline
\end{tabular}

Fonte: dados da pesquisa.

VIF: Variance Inflation Factor, AE: Autoeficácia; ED: Expectativa de Desempenho; EE: Expectativa de Esforço; IC: Intenção de Continuar; MH: Motivação Hedônica; QI: Qualidade da Informação; QS: Qualidade do Sistema.

Tabela 4 - Validade discriminante no nível dos construtos após a exclusão de qualidade do sistema.

\begin{tabular}{l|c|c|c|c|c|c}
\hline \multicolumn{7}{c}{ Validade Discriminante } \\
\hline Construtos & AE & ED & EE & IC & MH & OI \\
\hline $\mathrm{AE}$ & 0,871 & & & & & \\
\hline $\mathrm{ED}$ & 0,631 & 0,902 & & & & \\
\hline $\mathrm{EE}$ & 0,666 & 0,673 & 0,903 & & & \\
\hline $\mathrm{IC}$ & 0,673 & 0,717 & 0,585 & 0,860 & & \\
\hline $\mathrm{MH}$ & 0,626 & 0,744 & 0,766 & 0,680 & 0,893 & \\
\hline $\mathrm{QI}$ & 0,646 & 0,754 & 0,607 & 0,755 & 0,647 & 0,833 \\
\hline
\end{tabular}

Fonte: dados da pesquisa.

AE: Autoeficácia; ED: Expectativa de Desempenho; EE: Expectativa de Esforço; IC: Intenção de Continuar; MH: Motivação Hedônica; QI: Qualidade da Informação.

Tabela 5 - Diagnóstico de colinearidade.

\begin{tabular}{l|c}
\hline Dimensão & VIF \\
\hline $\mathrm{AE}$ & 2,202 \\
\hline $\mathrm{ED}$ & 3,232 \\
\hline $\mathrm{EE}$ & 2,872 \\
\hline $\mathrm{IC}$ & - \\
\hline $\mathrm{MH}$ & 3,201 \\
\hline $\mathrm{QI}$ & 2,645 \\
\hline
\end{tabular}

Fonte: dados da pesquisa.

VIF: Variance Inflation Factor, AE: Autoeficácia; ED: Expectativa de Desempenho; EE: Expectativa de Esforço; IC: Intenção de Continuar; MH: Motivação Hedônica; QI: Qualidade da Informação. 
entre moderado $(0,50)$ e robusto $(0,75)$ (Hair Junior et al., 2014). A Tabela 6, apresenta a análise do modelo estrutural.

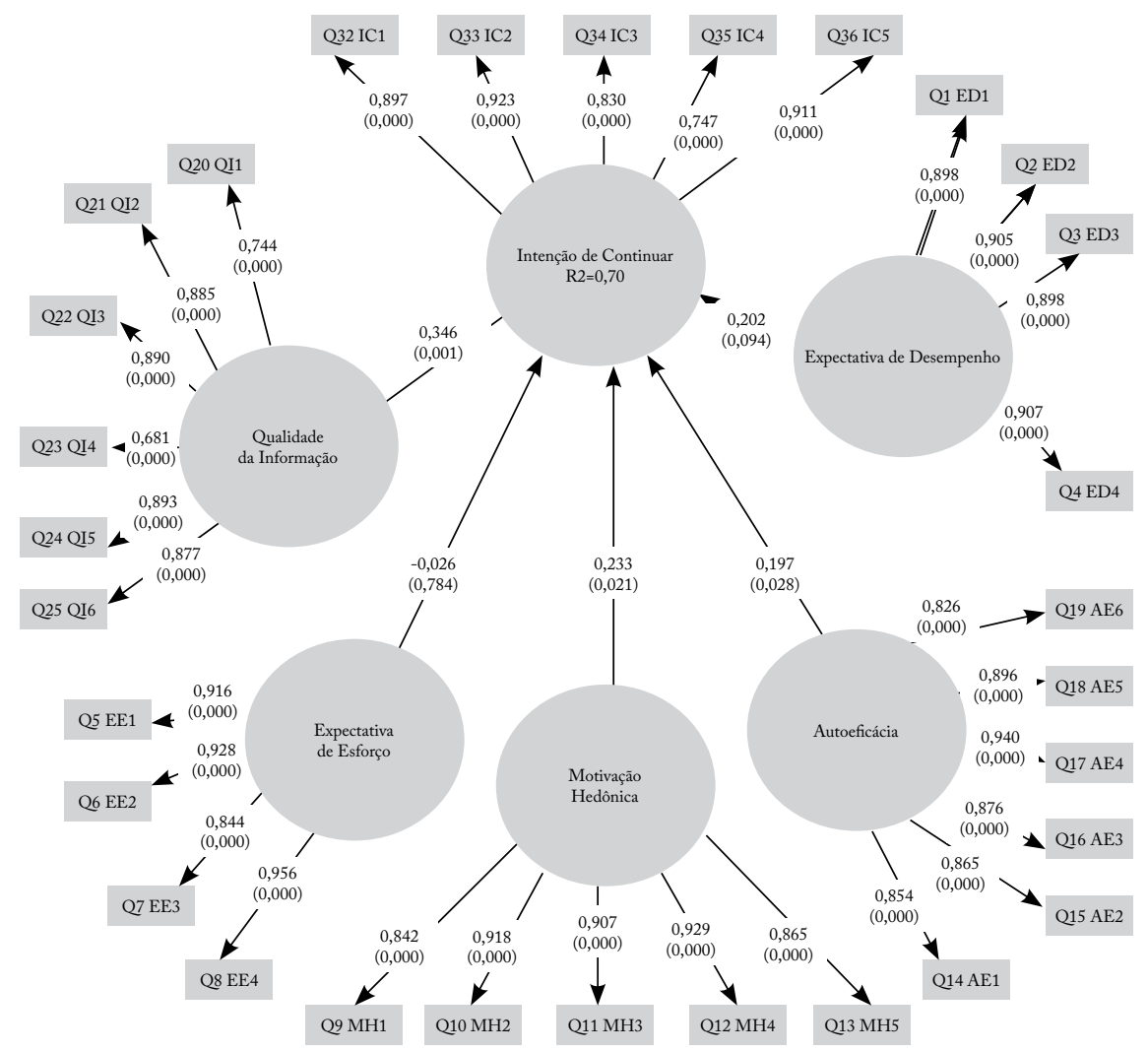

Figura 4-Modelagem final.

Fonte: dados da pesquisa.

Tabela 6 - Análise do modelo estrutural.

\begin{tabular}{|c|c|c|c|c|c|c|}
\hline Dimensões & Carga & $\mathrm{R}^{2}$ da IC & $p$-value & Teste T & $\mathrm{Q}^{2}$ & $f^{2}$ \\
\hline $\mathrm{AE} \rightarrow \mathrm{IC}$ & 0,197 & \multirow{5}{*}{0,70} & $0,028^{*}$ & 2,210 & \multirow{5}{*}{0,5} & 0,059 \\
\hline $\mathrm{ED} \rightarrow>\mathrm{IC}$ & 0,202 & & 0,094 & 1,680 & & 0,042 \\
\hline $\mathrm{EE} \rightarrow \mathrm{IC}$ & $-0,026$ & & 0,784 & 0,274 & & 0,001 \\
\hline $\mathrm{MH} \rightarrow \mathrm{IC}$ & 0,233 & & $0,021^{*}$ & 2,324 & & 0,056 \\
\hline $\mathrm{QI} \rightarrow \mathrm{IC}$ & 0,346 & & $0,001^{* * *}$ & 3,227 & & 0,145 \\
\hline
\end{tabular}

Fonte: dados da pesquisa.

IC: Intenção de Continuar; AE: Autoeficácia; ED: Expectativa de Desempenho; EE: Expectativa de Esforço; MH: Motivação

Hedônica; QI: Qualidade da Informação.

*nível de significância: 0,05; **nível de significância: 0,01; ***nível de significância: 0,001. 
$\mathrm{O} p$-value indicou três fatores com relações positivas e significativas com a retenção: qualidade da informação $\left(0,346 ; p=0,001^{* * *}\right)$, motivação hedônica $(0,233$; $\left.p=0,021^{*}\right)$ e autoeficácia $\left(0,197 ; p=0,028^{*}\right)$. Duas relações não foram significantes: expectativa de desempenho $(0,094 ; p=0,094)$ e expectativa de esforço $(-0,026$; $p=0,784)$; estas não apresentaram relações significantes com a intenção de continuar o curso on-line (Hair Junior et al, 2014).

$\mathrm{O}$ modelo apresentou o valor de $\mathrm{Q}^{2}$ de 0,50 , fornecendo suporte para a indicação de relevância preditiva do modelo, mas o $\mathrm{f}^{2}$ indicou que os construtos apresentaram baixa utilidade para o ajuste do modelo (Hair Junior et al., 2014).

Dentre as relações propostas, a mais intensa se deu entre a qualidade da informação e a intenção de continuar o curso on-line $(0,346 ; p=0,001)$. Isso indica que a retenção se deve especialmente a aspectos relacionados ao conteúdo, tais como as informações serem de fácil entendimento $(0,893)$, relevantes à aprendizagem $(0,890)$, confiáveis em termos de fonte e conteúdo $(0,885)$, atualizadas $(0,877)$, exatas e livres de erros $(0,744)$ e suficientes para a aprendizagem $(0,681)$.

A segunda relação mais importante ocorreu entre a motivação hedônica e a intenção de continuar o curso on-line $(0,233 ; p=0,021)$. Esse resultado sugere que um sistema prazeroso $(0,929)$, agradável $(0,918)$, interessante $(0,907)$, que faz o estudante nem perceber o tempo passar $(0,865)$ e divertido $(0,842)$ mantém relação positiva e significativa com a retenção dos alunos no curso on-line.

A última relação confirmada ocorreu entre a autoeficácia e a intenção do aluno de continuar o curso on-line $(0,197 ; p=0,028)$. Apesar de ter apresentado relação de menor intensidade, os indicadores: confiança dos alunos sobre a própria capacidade de acessar os slides disponíveis no sistema (0,940), participar dos quizzes $(0,896)$, assistir às aulas virtuais $(0,876)$, procurar informações nos links do sistema $(0,865)$, navegar seguindo ícones $(0,854)$ e acessar as provas on-line $(0,826)$ também se mostraram positivamente relacionados com a retenção dos alunos no curso on-line pesquisado.

\section{DISCUSSÃO DOS RESULTADOS}

Os resultados dos testes de hipótese indicam que a relação entre os construtos proposta no modelo encontrou apoio parcial, já que apenas três relações encontraram suporte estatístico.

A hipótese $\mathrm{H1}$ a - bá uma relação positiva entre a expectativa de desempenho $e$ a retenção de alunos em cursos on-line, não foi suportada. Os alunos concordam que o sistema do curso melhora o seu desempenho nas atividades de aprendizagem (teste de médias com pontuação alta $[5,58]$ ); no entanto, esse fator não se mostrou relevante para a permanência dos alunos no curso.

Esse resultado contrariou suposições preconizadas nos estudos seminais sobre a prevalência da importância do fator expectativa de desempenho sobre os demais fatores, já que a amostra estudada possui perfil semelhante ao citado por Venkatesh et al. (2003): homens, de elevado nível educacional e com experiência em cursos on-line. Esse perfil tende a ser mais pragmático, orientado por critérios utilitários e por necessidades de realização, fatores diretamente relacionados aos 
do construto expectativa de desempenho (Venkatesh, Morris e Ackerman, 2000; Tarhini, Hone e Liu, 2014).

Por outro lado, Venkatesh et al. (2003) identificaram que a expectativa de desempenho é mais influente em indivíduos mais jovens, diferente do perfil pesquisado neste estudo (faixa etária acima dos 30 anos).

$\mathrm{O}$ resultado contraria também achados sustentados empiricamente por Ong, Lai e Wang (2004), Chiu e Wang (2008) e Dečman (2015), pesquisadores de cursos on-line. Ong, Lai e Wang (2004) identificaram um efeito positivo entre a expectativa de desempenho e a intenção comportamental de uso de cursos on-line in company para engenheiros.

Infere-se que cursos do tipo in company ou obrigatórios para progressão na carreira podem apresentar maior valorização do fator expectativa de desempenho. $O$ fato desta pesquisa ter avaliado alunos de cursos do tipo livre pode ter levado a outras motivações percebidas como mais importantes pelos respondentes, como a busca pelo conhecimento, e não pelo certificado, indicando uma nova possibilidade de pesquisa.

Chiu e Wang (2008) verificaram relação positiva entre a expectativa de desempenho e a intenção de continuar a aprendizagem baseada na web junto a universitários em cursos on-line de aprendizagem continuada. Uma possível explicação vem do fato de esses estudantes serem menos experientes (77\% realizavam pela primeira vez um curso on-line), levando-os a valorizar critérios como agilidade e praticidade obtidos a partir do uso da tecnologia, perspectiva já apontada por Chen et al. (2011), ao constatarem que o impacto da expectativa de desempenho é ainda maior para os usuários com menos experiência em cursos on-line.

Dečman (2015) identificou a expectativa de desempenho como fator de influência mais importante em ambientes de e-learning. Observa-se, no entanto, que a amostra foi constituída por universitários do primeiro semestre, com idades entre 18 e 19 anos, em que 70\% eram do sexo feminino. Venkatesh, Morris e Ackerman (2000), Venkatesh et al. (2003) e Wang, Wu e Wang (2009) enfatizam que a diferença de resultados pode ser influenciada por dessas características de perfil (público jovem e feminino).

Também contrariando a literatura, a segunda hipótese do estudo, $H 1 b-$ há uma relação positiva entre a expectativa de esforço e a retenção de alunos em cursos on-line, não foi suportada.

Apesar de esse construto ter obtido uma média alta $(5,72)$, indicando que os estudantes pesquisados consideram o sistema do curso fácil de usar, os alunos não consideraram esse critério relevante para a sua permanência no curso. Esse resultado também foi imprevisto, já que os teóricos de base apontam como usual uma relação positiva entre a expectativa de esforço e a permanência na atividade.

No entanto, ao se observar o perfil da amostra estudada, é possível encontrar explicações. Venkatesh, Morris e Ackerman (2000) afirmam que os usuários mais experientes são menos sensíveis à expectativa de esforço, uma vez que apresentam menor grau de ansiedade, refletindo melhora na atitude geral em relação ao sistema. A partir do momento em que os fatores ambientais se tornam mais familiares, a intenção comportamental passa a refletir as experiências do indivíduo, fazendo com que a intenção se torne menos provisória. 
De modo geral, um maior conhecimento prévio sobre o uso do sistema, neste caso experiências anteriores na realização de cursos on-line, permite aos usuários manterem o foco sobre o conteúdo a ser aprendido, liberando-os de ter de aprender também a usar o sistema (Cohen e Levinthal,1990). Usuários mais experientes não percebem a expectativa de esforço como uma questão tão importante. $\mathrm{O}$ aumento da experiência fortalece a intenção de uso e enfraquece o efeito da expectativa de esforço, tornando-a mais relevante para indivíduos menos experientes (Taylor e Todd, 1995, Venkatesh et al., 2003). Da mesma forma e consoante ao perfil da amostra deste estudo, Venkatesh et al. (2003) apontam que a expectativa de esforço se mostra mais relevante para públicos com menor nível de escolaridade.

Por outro lado, em relação à idade, os resultados aqui encontrados divergem dos propostos pela UTAUT, que apontam uma maior influência do construto expectativa de esforço sobre usuários mais velhos, que, em teoria, não cresceram usando a tecnologia, como os nativos digitais, preferindo sistemas mais fáceis de usar (Venkatesh et al., 2003).

Ainda no que se refere ao perfil, Venkatesh et al.(2003) relatam que a relação entre expectativa de esforço e intenção de usar um sistema é mais forte nas mulheres do que nos homens. Os resultados para esse construto, por ser a amostra composta em sua maioria pelo sexo masculino, encontra amparo na teoria de Venkatesh et al. (2003), que creditam às mulheres um sentimento maior de ansiedade com o uso da tecnologia.

Quanto aos estudos empíricos em contexto de cursos on-line, vários deles, como os de Roca e Gagné (2008), Chiu e Wang (2008) e Sun et al. (2008), diferentemente do resultado que se obteve, também verificaram que a intenção de permanecer na aprendizagem baseada na web é influenciada pela expectativa de esforço. Roca e Gagné (2008) identificaram a importância da expectativa de esforço junto a 166 estudantes de cursos livres. $O$ fato de a amostra possuir uma quantidade maior de mulheres, $53 \%$, pode ter influenciado.

Na pesquisa de Sun et al. (2008), a expectativa de esforço se mostrou relevante para alunos jovens e com pouca experiência em cursos on-line. Chiu e Wang (2008) verificaram que a expectativa de esforço está positivamente relacionada à intenção dos estudantes de continuar o $e$-learning junto a alunos menos experientes. A menor experiência pode tê-los levado a valorizar critérios como facilidade de uso, perspectiva já apontada por Taylor e Todd (1995) e Venkatesh et al. (2003), ao constatarem que o impacto da expectativa de esforço é ainda maior para os usuários com menos experiência no uso de sistemas.

Por outro lado, estudos empíricos como os de Lee, Cheung e Chen (2005), junto a universitários de Hong Kong, Van Raaij e Schepers (2008), com participantes chineses de MBA on-line, Osubor e Chiemeke (2015), com universitários da Nigéria, e Nguyen, Nguyen e Cao (2014), com alunos de e-learning do Vietnã, não evidenciaram a relevância do construto expectativa de esforço.

Verifica-se que usar a internet, para os respondentes deste estudo, não é uma preocupação primordial. Segundo Dominici e Palumbo (2013), plataformas amigáveis e fáceis de usar já são consideradas como direito adquirido pelo usuário. Dessa forma, sua presença não determina a satisfação, apenas a sua ausência traria 
insatisfação, já que o usuário toma essa presença como certa. Assim, mesmo que para esta amostra o fator expectativa de esforço não tenha se mostrado relacionado à retenção, ratifica-se a importância de manter o ambiente amigável e fácil de usar.

O nível educacional do aluno (Agarwal e Prasad, 1998) e as habilidades técnicas prévias no uso da tecnologia (Pituch e Lee, 2006) podem afetar a permanência em cursos on-line. Gestores de cursos on-line não podem dar como certo que todos os alunos saberão intuitivamente acessar e navegar na plataforma virtual de aprendizagem, devendo, assim, facilitar esse processo ao máximo (Harasim et al., 2005), especialmente em projetos cujas interações face a face são ausentes (Rezaei et al., 2008; Joo, Joung e Kim, 2013).

A terceira hipótese, $H 1 c$ — há uma relação positiva entre a motivação hedônica $e$ a retenção de alunos em cursos on-line, foi suportada, confirmando a premissa dos teóricos que propuseram a inserção do construto UTAUT2 (Venkatesh, Thong e $\mathrm{Xu}, 2012)$ e colaborando com achados empíricos de Lee, Cheung e Chen (2005), com universitários de Hong Kong, Chiu e Wang (2008), com universitários de Taiwan, Zhang, Zhao e Tan (2008), com alunos de cursos on-line da China, e Nguyen, Nguyen e Cao (2014) com universitários da Arábia Saudita. Esses estudos verificaram que a ludicidade e o prazer com o uso da tecnologia influenciam a intenção dos alunos de usar o e-learning.

$\mathrm{O}$ fato de a amostra deste estudo ser composta por estudantes experientes em cursos on-line pode ter aumentado a motivação hedônica. Conforme Murray e Bellman (2011), conhecimentos anteriores afetam as experiências hedônicas, já que permitem ao usuário se concentrar apenas em seus interesses, sem a necessidade de ter de aprender etapas mecanizadas para usar o sistema.

O perfil predominantemente masculino da amostra também pode ter levado à valorização do construto motivação hedônica. Segundo Rudell (1989), os homens se sentem mais seguros com o uso da tecnologia, o que permite que a desfrutem com maior prazer, enquanto as mulheres percebem o uso da tecnologia como uma ferramenta para completar tarefas.

$\mathrm{O}$ fato de a perspectiva hedonista ter se sobressaído à utilitarista pode ser influência do contexto pesquisado. Conforme Pedrotti e Nistor (2016), as motivações comportamentais são diferentes em contextos educacionais e laborais. Normalmente, o comportamento no local de trabalho é conduzido por motivadores extrínsecos, como salário, posição hierárquica e status social. Já em contextos educativos, motivadores intrínsecos, como realização pessoal e prazer, desempenham um papel mais importante.

Com relação às contribuições práticas, mesmo que neste estudo a relação entre a motivação hedônica e a intenção de o aluno permanecer no curso não tenha sido a mais forte, sua influência deve ser levada em conta por gestores de cursos on-line. Desenvolvedores e designers de sites de cursos baseados na web devem empregar formas de reduzir a monotonia e explorar características lúdicas, fornecendo ferramentas ou mecanismos bem desenhados que atendam a essa perspectiva apontada nos resultados da pesquisa. Conforme Chiu e Wang (2008), estudantes são intrinsecamente motivados à aprendizagem on-line quando há interesse e prazer em realizá-la. 
Motivadores extrínsecos e intrínsecos são tipos diferentes de condutores capazes de influenciar o comportamento (Lee, Cheung e Chen, 2005). A preferência por aspectos utilitários ou hedônicos pode auxiliar os desenvolvedores de sistemas a adotarem táticas específicas para o estímulo ao seu uso em cursos on-line. No caso dos resultados deste estudo, a motivação hedônica prevaleceu sobre os critérios utilitaristas sugeridos pelo fator expectativa de desempenho. Assim, táticas que promovam a inclusão de conteúdos, como imagens animadas, foco em cores, sons e layouts esteticamente atraentes, devem se sobressair a layouts puramente utilitaristas que buscam evitar a distração do usuário (van der Heijden, 2004).

Quanto à teoria, os resultados aos quais se chegou contribuem por ratificarem a importância da motivação hedônica para a permanência dos usuários na atividade que estão realizando em contextos educacionais, confirmando resultados já preconizados na literatura.

A quarta hipótese, H1d - há uma relação positiva entre a autoeficácia e a retenção de alunos em cursos on-line, também foi suportada. Assim como em estudos seminais (Bandura, 1986; Venkatesh et al., 2003), a relação positiva entre a autoeficácia e a retenção também encontra amparo em estudos empíricos como os de Wang e Newlin (2002) e Holder (2007). Ambos verificaram, junto a estudantes americanos, que alunos mais persistentes obtêm pontuação mais elevada em medidas de autoeficácia do que os desistentes.

Em consonância, Chiu e Wang (2008) verificaram, junto a universitários de Taiwan, e Alenezi, Abdul Karim e Veloo (2010), junto a universitários da Arábia Saudita, a capacidade do construto de influenciar a intenção dos alunos de usar o $e$-learning.

Os resultados supramencionados levam a crer que autoeficácia tecnológica desempenha um papel importante na aceitação e utilização de sistemas de informação (Saleem, Beaudry e Croteau, 2011) e, neste caso, cursos on-line. A relação positiva entre a autoeficácia e a retenção também pode ser explicada pelo nível de experiência em cursos on-line indicado pelos respondentes deste estudo, fator que também os leva a apresentarem maior nível de autoeficácia, por serem mais experientes (Roca, Chiu e Martínez, 2006). A fonte de autoeficácia deriva da evolução de desempenhos resultantes de experiências anteriores (Bandura, 1986). A experiência melhora a autoeficácia (Torkzadeh, Chang e Demirhan, 2006). Assim, indivíduos mais experientes, como no caso da amostra estudada, tendem a ser mais autoconfiantes no desempenho de tarefas correlatas.

Apesar de a relação entre o construto autoeficácia e a retenção ter se confirmado neste estudo, observa-se que tal relação apresentou um impacto considerado pequeno. Esse baixo impacto pode ter sido afetado pelo nível mais elevado de experiência e qualificação educacional apresentado pela amostra. No caso de públicos menos experientes, os gestores de cursos on-line podem realizar avaliações para diagnosticar as dificuldades dos estudantes e, posteriormente, oferecer apoio tecnológico e capacitações destinadas a aumentar a confiança do aluno na aprendizagem on-line, melhorando a sua proficiência e competência de forma a fazê-lo permanecer no curso (Carruth et al., 2010; Park, Perry e Edwards, 2011). 
Para a teoria, os achados ratificam a importância do fator autoeficácia apontado na literatura, mas indicam que a força da relação pode ser influenciada pela experiência e pelo nível de escolaridade da amostra.

A hipótese $H 2 a$ - há uma relação positiva entre a qualidade da informação e a retenção de alunos em cursos on-line também foi suportada. Coerente à afirmação de que a qualidade da informação favorece uma melhor experiência e intensifica o uso do sistema (Roca, Chiu e Martínez, 2006; Martínez-Torres et al., 2008), o coeficiente de caminho $(0,34)$ e a significância estatística $(p=0,001)$ indicam que essa é a relação mais relevante entre as pesquisadas.

Esse resultado é consoante com o perfil dos respondentes aqui estudados. Espera-se de indivíduos mais experientes, mais velhos e com nível de escolaridade alto apresentem um nível de exigência maior em termos de conteúdo. Cabe aos gestores direcionar seus esforços e investimentos ao desenvolvimento de materiais e conteúdos relevantes, com maior nível de desafio intelectual para atender a esse perfil mais exigente de público.

Os achados indicam que a qualidade da informação leva os alunos a permanecerem no curso on-line, confirmando os estudos de Shee e Wang (2008), Alshare et al. (2011), Saba (2012), Machado-da-Silva (2013), Mohammadi (2015) e Ali, Yaacob e Endut (2016).

Conforme Shee e Wang (2008), alunos tendem a dar grande valor à qualidade do conteúdo observando aspectos como organização, apresentação, interatividade, clareza, quantidade adequada, utilidade, flexibilidade e profundidade da informação. Para Alshare et al. (2011), a qualidade da informação foi o fator de maior influência no uso do sistema junto a estudantes de e-learning e se mostrou mais significativa para indivíduos do sexo masculino. Saba (2012) verificou que a qualidade da informação afeta tanto o uso do sistema do curso on-line quanto a satisfação e o comportamento de aprendizagem dos alunos.

O fator qualidade da informação também obteve maior impacto nos construtos satisfação e uso do sistema de cursos online nas pesquisas de Machado-da-Silva (2013), com estudantes de todas as regiões do Brasil, Mohammadi (2015), com estudantes de quatro universidades do Irã, e Ali, Yaacob e Endut (2016), com alunos da Arábia Saudita.

Com relação à parte prática, esse resultado contribui por indicar aos gestores de cursos on-line, cujo público possua níveis mais elevados de experiência e nível educacional, conforme o analisado neste estudo, a importância da concentração das decisões de investimento no desenvolvimento de materiais instrucionais com conteúdos claros, bem escritos e relevantes. Os respondentes desta amostra são especialistas em suas áreas de atuação. Isso exige que as informações não sejam superficiais, e sim, filtradas, avaliadas e contextualizadas, aprofundando o que de fato é relevante (Roth, 2015). É preciso oferecer ao estudante o que ele realmente busca, neste caso, conteúdo de qualidade.

É necessário entender que a apresentação da informação remete à tecnologia e é de responsabilidade do designer instrucional. Já a qualidade da informação não é dependente da tecnologia, e sim dos desenvolvedores de conteúdo do curso on-line, 
que precisam se preocupar com a criação de materiais úteis e essenciais para atender a essa exigência dos alunos (Saba, 2012).

A facilidade de entendimento foi o atributo relacionado ao construto qualidade da informação mais valorizado pelos respondentes. $\mathrm{O}$ acesso a materiais de apoio e conceitos de aprendizagem é essencial aos estudantes de cursos on-line. Especialmente nessa modalidade, é preciso gerar conteúdo baseado em textos dialógicos e autoexplicativos, acompanhado por sugestões de links e materiais complementares (Roca, Chiu e Martínez, 2006; Alshare et al., 2011). Tal resultado indica que, mesmo o curso sendo oferecido a um público mais experiente e com nível educacional elevado, é preciso investir na forma de apresentação da informação, para que critérios como clareza, concisão, compatibilidade e desenho dos dados contribuam para o entendimento dos conteúdos. O conteúdo do curso pode ser complexo, mas a apresentação das informações deve ser clara.

Assim, conforme indicado por Sousa e Coutinho (2009), há a necessidade de o conteudista tomar decisões de forma conjunta com o designer do sistema, já que a formatação dessas informações se dá a partir de interfaces e linguagens nem sempre familiares ao desenvolvedor de conteúdo.

Uma recomendação sugerida por Pinto (2007) se refere à valorização dos indicadores que se mostram imutáveis, apesar da subjetividade do critério qualidade, como o rigor científico e a capacidade da informação de atender às necessidades de aprendizagem do estudante.

Outro fator importante é citado por Lin e Wang (2012): não apenas materiais e conteúdos de ensino precisam ser valorizados. As avaliações, a comunicação da instituição com os alunos, a divulgação de cronogramas, horários e notas por meio do quadro de avisos do sistema, $e$-mails etc., também são entendidos como informação e avaliados em termos de qualidade, exigindo atenção, clareza e detalhamento na sua elaboração.

Para a teoria, os achados sobre a importância da qualidade da informação ratificam o que vem sendo preconizado pela literatura sobre a influência desse fator na permanência dos alunos no curso. Além disso, a valorização da qualidade da informação aumenta conforme aumentam o nível educacional e a experiência do público avaliado.

No caso desta pesquisa, pode-se entender que os respondentes consideram o conteúdo do curso mais importante do que fatores como autoeficácia ou motivação hedônica. Assim, mais importante do que proporcionar aos estudantes sistemas de aprendizagem on-line amigáveis, é fornecer-lhes informações de alta qualidade (Roca, Chiu e Martínez, 2006; Alshare et al., 2011). A observação desses critérios pelos desenvolvedores de conteúdos dos cursos on-line colabora para o atendimento a padrões qualitativos relacionados à informação e valorizados pelo perfil de público aqui estudado.

Realça-se que o fator qualidade do sistema não pode ser analisado por motivos de colinearidade, impedindo que se faça qualquer inferência.

\section{CONCLUSÃO}

Por uma perspectiva que atribui à gestão dos cursos on-line a capacidade de melhorar os índices de permanência do aluno, este estudo objetivou avaliar, com foco 
na gestão, a relação entre os fatores de aceitação da tecnologia, comportamentais e técnicos e a retenção de alunos em cursos on-line. Os achados fornecem várias implicações teóricas e práticas importantes para a gestão de sucesso da retenção em cursos online.

Como contribuição teórica, verificou-se que a proposta de associar variáveis de aceitação da tecnologia à retenção em cursos on-line é plausível. Tanto fatores comportamentais, representados pela motivação hedônica e autoeficácia, quanto o fator técnico qualidade da informação foram positivamente relacionados com a retenção de alunos nos cursos online. Isso demonstra que a análise conjunta de fatores pertencentes a concepções teóricas diferentes pode ser relevante para indicar novas possibilidades de variáveis não previstas nos modelos de forma isolada, mas importantes na avaliação dos usuários.

Usar um modelo que apresente uma taxonomia gerenciável de variáveis diferentes como referencial teórico ajuda gestores e pesquisadores a ampliarem o rol de opções sobre os fatores que levam os alunos a continuarem o curso on-line, o que facilita a adoção mais assertiva de técnicas e processos pelos quais as novidades são implementadas.

Comprovou-se a capacidade de fatores dos modelos UTAUT e D\&M serem passíveis de adaptação ao contexto educacional e capazes de explicar a retenção de alunos nos cursos on-line, mesmo que alguns deles, reconhecidamente relevantes em outros estudos semelhantes, não tenham se comportado da maneira como foram apresentados por seus autores de base.

Apesar de, teoricamente, o modelo ter sido construído para que todas as hipóteses apresentassem relações positivas com a retenção, quando fatores comportamentais e técnicos são analisados de forma conjunta, verifica-se que os fatores expectativa de desempenho e expectativa de esforço não apresentaram relação com a retenção.

Uma possível explicação reside no fato de o uso cotidiano da internet ou o nível elevado de experiência em cursos on-line dos respondentes já ter dirimido as possíveis causas de ansiedade relacionadas ao uso da tecnologia, tornando essas questões corriqueiras ou superadas. Assim, para o perfil de respondentes desta pesquisa, quando fatores relacionados à melhoria de desempenho e facilidade de uso são confrontados com fatores técnicos, como qualidade da informação, acabam perdendo valor.

No entanto, infere-se que os fatores expectativa de desempenho e expectativa de esforço não devem ser desconsiderados em outros estudos sobre retenção em cursos on-line, já que poderão se mostrar eficientes para um perfil diferente de respondentes. Públicos menos experientes, realizando outros tipos de curso, em outras áreas, com maior duração ou outro nível educacional, como cursos de graduação, por exemplo, poderão priorizar fatores diferentes dos valorizados pelos respondentes desta pesquisa.

De maneira geral, os resultados contribuem para o entendimento da relevância de fatores comportamentais e técnicos, como a motivação hedônica, a autoeficácia e, em especial, a qualidade do sistema, para a retenção de alunos em cursos on-line. Isso colabora para que os gestores das instituições de ensino possam ajustar estratégias e tomar decisões de investimentos mais assertivas, envolvendo especialmente esses fatores. 
Quanto à gestão universitária, este estudo contribui para ampliar o número ainda incipiente de estudos que analisam, pela perspectiva da gestão, o problema da baixa retenção de alunos em cursos on-line.

\section{RECOMENDAÇÕES}

A escassez de estudos desenvolvidos pela perspectiva da gestão, na modalidade on-line, aponta a necessidade de novos caminhos de pesquisas que possam auxiliar os gestores, inclusive a partir de outras variáveis de estudo, além das sugeridas pelas teorias de aceitação e uso da tecnologia. Sugere-se também, a aplicação do estudo em outras realidades, como em cursos de graduação, cujo perfil de alunos tende a ser mais jovem e menos experiente. Dessa forma, fatores como expectativa de esforço, expectativa de desempenho e autoeficácia talvez se mostrem mais influentes na intenção de permanência do aluno no curso. Realizar análises longitudinais pode ser útil para estudar o fenômeno da retenção de alunos ao longo do tempo.

\section{LIMITAÇÕES DA PESQUISA}

Valer-se apenas da percepção dos respondentes pode se tornar uma limitação, se alguns dos respondentes possuírem um conhecimento limitado a respeito do fenômeno investigado, distorcendo a realidade. Adotar uma pesquisa com corte transversal pode limitar os resultados em função de a percepção dos respondentes nem sempre permanecer inalterada ao longo do tempo. A ausência de uma teoria específica sobre a aceitação de tecnologias educacionais levou à escolha de modelos originalmente desenvolvidos para a análise de outros contextos, como o laboral (UTAUT e D\&M) e o de consumo (UTAUT2).

Por fim, a amostra do estudo representa apenas $17 \%$ da população. Além disso, apresenta pouca variação de sexo, idade, níveis de escolaridade e experiência dos respondentes, impedindo-a de ser usada como moderadora. Apesar de o Modelo de Fatores de Sucesso de Sistemas de Informação de DeLone e McLean (D\&M) e de a maioria dos estudos empíricos sobre aceitação da tecnologia e retenção não usarem variáveis demográficas como moderadoras ou não terem encontrado efeito significativo no seu uso, a UTAUT sugere essa análise.

\section{REFERÊNCIAS}

Аквав, F. What affects students' acceptance and use of technology? Qatar campus: Dietrich College Honors Theses-Carnegie Mellon University, 2013.

Agarwal, R.; Prasad, J. A conceptual and operational definition of personal innovativeness in the domain of information technology. Information Systems Research, v. 9, n. 2, p. 204-215, 1998.

Albertin, A. L.; Brauer, M. Resistência à educação a distância na educação corporativa. Revista de Administração Pública, v. 46, n. 5, p. 1367-1389, 2012. 
Ali, M.; YaAcob, R. A. I. B. R.; Endut, M. N. A. B. Understanding the academic use of social media: integration of personality with TAM. Journal of Theoretical and Applied Information Technology, v. 90, n. 1, p. 1, 2016.

Allen,I.E.; Seaman, J. Online nation: Five years of growth in online learning. Needhan, MA: Sloan Consortium, 2007.

Alshare, K. A.; Freeze, R. D.; Lane, P. G.; Wen, H. J. The impacts of system and human factors on online learning systems use and learner satisfaction. Decision Sciences Journal of Innovative Education, v. 9, n. 3, p. 437-461, 2011.

Alshehri, M.; Drew, S.; Alhussain, T.; Alghamdi, R. The effects of website quality on adoption of e-government service: an empirical study applying UTAUT model using SEM. In: Australasian Conference on Information Systems, 23., 2012, Melbourn. Proceedings... 2012. Melbourn, Australia: ACIS 2012. p. 1-13.

Alenezi, A. R.; Abdul Karim, A. M.; Veloo, A. An empirical investigation into the role of enjoyment, computer anxiety, computer self-efficacy and internet experience in influencing the students' intention to use e-learning: a case study from Saudi Arabian Governmental Universities. Turkish Online Journal of Educational Technology, v. 9, n. 4, p. 22-34, 2010.

Arbaugh, J. B. Is there an optimal design for online MBA courses? Academy of Management Learning E Education, v. 4, n. 2, p. 135-149, 2005.

Associação Brasileira de Educação a Distância (ABED). Anuário estatístico de educação aberta e a distância, 2014/2015. 2016. Disponível em: <http://www.abed.org. $\mathrm{br} / \mathrm{site} / \mathrm{pt} / \mathrm{midiateca/censo \_ ead} />$. Acesso em: 18 jun. 2016.

Bandura, A. Social foundations of thought and action: a social cognitive theory. PrenticeHall, Inc, 1986.

Berger, J. B.; Lyon, S. C. College student retention: Formula for student success. Past to present: a historic look at retention. In A. Seidman (Ed.). Westport: Greenwood Publishing Group, 2005.

Bernardo, M.; Marimon, F.; Alonso-Almeida, M. Functional quality and hedonic quality: A study of the dimensions of e-service quality in online travel agencies. Information \& Management, v. 49, n. 7, p. 342-347, 2012.

Carruth, A. K; Broussard, P. C.; Waldmeier, V.P.; Gauthier, D. M.; Mixon, G. Graduate nursing online orientation course: Transitioning for success. The Journal of Nursing Education, v. 49, n. 12, p. 687-690, 2010.

Castro, J. M.; Ladeira, E. S. Gestão e planejamento de cursos a distância $(\mathrm{EaD})$ no Brasil: um estudo de casos múltiplos em três instituições de ensino superior. Gestão छ̋ Planejamento-GEP, v. 10, n. 2, p. 229-247, 2010.

Chen, L. S.; Kuan, C.J.; Lee, Y.-H.; Huang,H.-L. Applicability of the UTAUT model in playing online game through mobile phones: Moderating effects of user experience. First International Technology Management Conference. San Jose, CA, USA: IEEE,2011.

Cheng, Y. Effects of quality antecedents on e-learning acceptance. Internet Research, v. 22, n. 3, p. 361-390, 2012. 
Chiv, C. M.; Hsu, M. H.; Sun, S. Y.; Lin, T. C.; Sun, P. C. Usability, quality, value and e-learning continuance decisions. Computers E Education, v. 45, n. 4, p. 399-416, 2005.

.; Wang, E. T. G. Understanding web-based learning continuance intention: The role of subjective task value. Information \& Management, v. 45, n. 3, p. 194-201, 2008. Cohen, W.M.; Levinthal, D. A. Absorptive capacity: A new perspective on learning and innovation. Administrative Science Quarterly, v. 35, p. 128-152, 1990.

Daudt, S. I. D.; Behar, P. A. A gestão de cursos de graduação a distância e o fenômeno da evasão. Educação, v. 36, n. 3, p. 412-421, 2013.

Duarte, A. L. F.; Vieira, P. R. C.; Silva, A. C. M. Satisfação do usuário de sistema de informação acadêmica: pesquisa com utilização de indicadores formativos. Revista $A D E M . M A D E$, v. 18, n. 3, p. 97-121, 2015.

Dečman, M. Modeling the acceptance of e-learning in mandatory environments of higher education: The influence of previous education and gender. Computers in Human Behavior, v. 49, p. 272-281, 2015.

Delone, W. H.; Mclean, E. R. Information systems success: The quest for the dependent variable. Information Systems Research, v. 3, n. 1, p. 60-95, 1992.

.;_____. The D\&M model of information systems success: a ten-year update. Journal of Management Information Systems, v. 19, n. 4, p. 9-30, 2003.

Dominici, G.; Palumbo, F. How to build an e-learning product: Factors for student/ customer satisfaction. Business Horizons, v. 56, n. 1, p. 87-96, 2013.

Fishbein, M.; Ajzen, I. Attitude, intention and behavior: an introduction to theory and research. Reading, MA: Addison-Wesley, 1975.v. 6. 562p.

Fornell, C.; LARCKER, D. F. Evaluating structural equation models with unobservable variables and measurement error. Journal of Marketing Research.v.18, n. 1, p.39-50, 1981.

Fozdar, B. I.; Kumar, L. S. Mobile Learning and Student Retention. International Review of Research in Open and Distance Learning, v. 8, n. 2, p. 1-18, 2007.

Freitas, K. S. Alguns estudos sobre evasão e persistência de estudantes. EccoS Revista Cientifica, v. 11, n. 1, p. 247-264, 2009.

Frezatti, F.; Aguiar, A. B.; Rezende, A. J. Relacionamento entre atributos da contabilidade gerencial e satisfação do usuário. Revista de Administração Mackenzie, v. 8, n. 2, p. 128-161, 2008.

Gupta, B.; Dasgupta, S.; Gupta, A. Adoption of ICT in a government organization in a developing country: An empirical study. The Journal of Strategic Information Systems, v. 17, n. 2, p. 140-154, 2008.

Hair Junior, J. F.; Hult, G. T. M.; Ringle, C.; Sarstedt, M. A primer on partial least squares structural equation modeling (PLS-SEM). Los Angeles: Sage Publications, 2014.

Harasim, L.; Teles, L. F; Turoff, M.; Hiltz, S. R. Redes de aprendizagem: um guia para ensino e aprendizagem online. São Paulo: Editora Senac, 2005.

Hill, R. P.; Gardner, M. P. The buying process: Effects of and on consumer mood states. Advances in Consumer Research, v. 14, n. 1, p. 408-410, 1987. 
Holder, B. An investigation of hope, academics, environment, and motivation as predictors of persistence in higher education online programs. The Internet and Higher Education, v. 10, n. 4, p. 245-260, 2007.

Hora, D. L. Gestão democrática na escola: artes e ofícios de participação coletiva. Campinas: Papirus, 1994.

Ifinedo, P. Understanding information systems security policy compliance: An integration of the theory of planned behavior and the protection motivation theory. Computers E Security, v. 31, n. 1, p. 83-95, 2012.

Joo, Y. J.; Joung, S.; Kim, E. K. Structural relationships among e-learners' sense of presence, usage, flow, satisfaction, and persistence. Journal of Educational Technology $\mathcal{E}^{\circ}$ Society, v. 16, n. 2, p. 310-324, 2013.

Joo, Y.J.; Joung, S.; Sim, W. J. Structural relationships among internal locus of control, institutional support, flow, and learner persistence in cyber universities. Computers in Human Behavior, v. 27, n. 2, p. 714-722, 2011.

KING, W. R.; HE,Jn. A meta-analysis of the technology acceptance model. Information E Management, v. 43, n. 6, p. 740-755, 2006.

Laguardia, J.; Portela, M.H. Evasão na educação a distância. Dropout in distance education. ETD-Educação Temática Digital, v. 11, n. 1, p. 349-379, 2009.

LEE, M. Explaining and predicting users' continuance intention toward e-learning: An extension of the expectation-confirmation model. Computers $E$ Education, v. 54, n. 2, p. 506-516, 2010.

Lee, M. K.; Cheung, C.; Chen, Z. Acceptance of Internet-based learning medium: the role of extrinsic and intrinsic motivation. Information E Management, v. 42, n. 8, p. 1095-1104, 2005.

LeE, Y.; CHOI, J. A structural equation model of predictors of online learning retention. The Internet and Higher Education, v. 16, p. 36-42, 2013.

Levy, Y. Comparing dropouts and persistence in e-learning courses. Computers $\mathbb{E}$ Education, v. 48, n. 2, p. 185-204, 2007.

Lin, K. E-learning continuance intention: Moderating effects of user e-learning experience. Computers E Education, v. 56, n. 2, p. 515-526, 2011.

Lin, W.; Wang, C. Antecedences to continued intentions of adopting e-learning system in blended learning instruction: A contingency framework based on models of information system success and task-technology fit. Computers $\mathcal{E}$ Education, v. 58, n. 1, p. 88-99, 2012.

Machado-Da-Silva, F. N. Fatores antecedentes da satisfação do aluno e do uso de sistemas virtuais de aprendizagem. 2013. 104f. Dissertação (Mestrado em Administração de Empresas) - Escola de Administração de Empresas de São Paulo, São Paulo, 2013.

Martín García, A. V. M.; Dujo, A. G. D.; Rodríguez, J. M. Factores determinantes de adopción de blended learning en educación superior. Adaptación del modelo UTAUT. Educación XX1, v. 17, n. 2, p. 217-240, 2014. 
Martínez-Torres, M. R.; Toral Marín, S. L.; Barrero García, F.; Gallardo VÁzquez, S.; Arias Oliva, M.; Torres, T. A technological acceptance of e-learning tools used in practical and laboratory teaching, according to the European higher education area 1. Behaviour E Information Technology, v. 27, n. 6, p. 495-505, 2008.

Mikalef, P.; Pappas, I. O.; Giannakos, M. N. Investigating Determinants of Video-Based Learning Acceptance. In: State-of-the-Art and Future Directions of Smart Learning. Springer Singapore, 2016. p. 483-491.

Mohamadali, N. A. K. S; Garibaldi, J. M. A novel evaluation model of user acceptance of software technology in healthcare sector. HEALTHINF: International Conference on Health Informatics, 3., 2010. Proceedings... Valencia, Spain, January 20-23, 2010. p. 392-397.

MoнAmmadi, H.Investigating users' perspectives on $e$-learning: an integration of TAM and IS success model. Computers in Human Behavior, v. 45, p. 359-374, 2015.

Motaghian, H.; Hassanzadeh, A.; Moghadam, D. K. Factors affecting university instructors' adoption of web-based learning systems: Case study of Iran. Computers $\mathcal{E}^{\circ}$ Education, v. 61, p. 158-167, 2013.

Murray, K. B.; Bellman, S. Productive play time: the effect of practice on consumer demand for hedonic experiences. Journal of the Academy of Marketing Science, v. 39, n. 3, p. 376-391, 2011.

Nguyen, T. D.; Nguyen, D. T.; Cao, T. H. Acceptance and use of information system: E-learning based on cloud computing in Vietnam. Information and Communication Technology. Springer Berlin Heidelberg, p. 139-149, 2014.

Njenga, J. K.; Fourie, L. C. H. The myths about e-learning in higher education. British Journal of Educational Technology, v. 41, n. 2, p. 199-212, 2010.

ONG, C.; LAI, J.; WANG, Y. Factors affecting engineers' acceptance of asynchronous e-learning systems in high-tech companies. Information $\&$ Management, v. 41, n. 6, p. 795-804, 2004.

Osubor, V. O.; Chiemere, S. C. The impacts of information culture on e-learning innovation adoption in learning institutions in Nigeria. African Journal of Computing and ICT, v. 8, n. 1, p. 17-26, 2015.

Park, C. L.; Perry, B.; Edwards, M. Minimizing attrition: strategies for assisting students who are at risk of withdrawal. Innovations in Education and Teaching International, v. 48, n. 1, p. 37-47, 2011.

Patterson, B.; McFadden, C. Attrition in online and campus degree programs. Online Journal of Distance Learning Administration, v. 12, n. 2, 2009.

Pituch, K. A.; Lee, Y. The influence of system characteristics on e-learning use. Computers E Education, v. 47, n. 2, p. 222-244, 2006.

Pedrotti, M.; Nistor, N. User motivation and technology acceptance in online learning environments. European Conference on Technology Enhanced Learning. Springer International Publishing, 2016. p. 472-477.

Premkumar, G.; Bhattacherjee, A. Explaining information technology usage: A test of competing models. Omega, v. 36, n. 1, p. 64-75, 2008. 
Ramayah, T.; Ahmad, N.H.; Lo, M. The role of quality factors in intention to continue using an e-learning system in Malaysia. Procedia-Social and Behavioral Sciences, v. 2, n. 2, p. 5422-5426, 2010.

Reichenheim, M. E.; Moraes, C. L. Operacionalização de adaptação transcultural de instrumentos de aferição usados em epidemiologia. Revista de Saúde Pública, v. 41, n. 4, p. 665-73, 2007.

Rezaei, M.; Mohammadi, H. M.; Asadi, A.; Kalantary, K. Predicting e-learning application in agricultural higher education using technology acceptance model. Turkish Online Journal of Distance Education, v. 9, n. 1, p. 85-95, 2008.

Ringle, C.M.; Silva, D.; Bido, D. S. Modelagem de equações estruturais com utilização do Smartpls. Revista Brasileira de Marketing, v. 13, n. 2, p. 56-73, 2014.

Roca,J.C.; Chiu, C.; Martínez, F.J. Understanding e-learning continuance intention: An extension of the Technology Acceptance Model. International Journal of HumanComputer Studies, v. 64, n. 8, p. 683-696, 2006.

.; GAGNÉ, M. Understanding e-learning continuance intention in the workplace: A self-determination theory perspective. Computers in Human Behavior, v. 24, n. 4, p. $1585-1604,2008$.

Rотн, R. Institutional strategies and practices for integrating learning technologies in the inner, outer and virtual spaces. International Journal of Learning, Teaching and Educational Research, v. 12, n. 3, p. 80-97, 2015.

Rudell, F. Do boys love their toys, and what do women want? an exploratory investigation of gender differences in attitudes toward new technology. Marketing Theory and Practice: Developments for the 90s, v. 5, p. 167-172, 1989.

SÁ, G. M.; PAdilha, M. Análise de modelos de gestão de educação a distância em universidades públicas do Brasil. In: Congresso Brasileiro de Ensino Superior a Distância, 10., Belém, 2013. Anais... Belém: ESUD, 2013.

SABA, T. Implications of E-learning systems and self-efficiency on students outcomes: a model approach. Human-Centric Computing and Information Sciences, v. 2, n. 1, p. 1, 2012. Saleem, H.; Beaudry, A.; Croteau, A. Antecedents of computer self-efficacy: A study of the role of personality traits and gender. Computers in Human Behavior, v. 27, n. 5, p. 1922-1936, 2011.

Schlemmer, E.; Saccol, A. Z.; Garrido, S. Um modelo sistêmico de avaliação de softwares para educação a distância como apoio à gestão de EaD. REGE Revista de Gestão, v. 14, n. 1, p. 77-91, 2007.

Sharma, S. K.; Joshi, A.; Sharma, H. A multi-analytical approach to predict the Facebook usage in higher education. Computers in Human Behavior, v. 55, p. 340-353, 2016.

Shee, D. Y.; Wang, Y. S. Multi-criteria evaluation of the web-based e-learning system: A methodology based on learner satisfaction and its applications. Computers E Education, v. 50, n. 3, p. 894-905, 2008.

Sun, P.; Tsai, R. J.; Finger, G.; Chen, Y. Y.; Yeh, D. What drives a successful e-learning? An empirical investigation of the critical factors influencing learner satisfaction. Computers E Education, v. 50, n. 4, p. 1183-1202, 2008. 
TAYloR, S.; TodD, P. A. Understanding information technology usage: A test of competing models. Information Systems Research, v. 6, n. 2, p. 144-176, 1995.

TARHIni, A.; Hone, K.; Liv, X. The effects of individual differences on $e$-learning users' behaviour in developing countries: A structural equation model. Computers in Human Behavior, v. 41, p. 153-163, 2014.

Torkzadeh, G.; Chang, J. C.; Demirhan, D. A contingency model of computer and Internet self-efficacy. Information E Management, v. 43, n. 4, p. 541-550, 2006.

Tsai, C. C.; Chuang, S. C.; Liang, J. C.; Tsai, M. J. Self-efficacy in Internet-based learning environments: A literature review. Journal of Educational Technology E Society, v. 14, n. 4, p. 222-240, 2011.

Urbach, N.; Smolnik, S.; Riempp, G. An empirical investigation of employee portal success. The Journal of Strategic Information Systems, v. 19, n. 3, p. 184-206, 2010.

VAN Der Heijden, H. User acceptance of hedonic information systems. MIS Quarterly, p. 695-704, 2004.

Van RaAiJ, E. M.; Schepers, J. J. L. The acceptance and use of a virtual learning environment in China. Computers E' Education, v. 50, n. 3, p. 838-852, 2008.

Venkatesh, V. Determinants of perceived ease of use: Integrating control, intrinsic motivation, and emotion into the technology acceptance model. Information Systems Research, v. 11, n. 4, p. 342-365, 2000.

.; Davis, F. D. A model of the antecedents of perceived ease of use: Development and test. Decision Sciences, v. 27, n. 3, p. 451-481, 1996.

;____. A theoretical extension of the technology acceptance model: Four longitudinal field studies. Management Science, v. 46, n. 2, p. 186-204, 2000.

Venkatesh, V.; Morris, M. G.; Ackerman, P. L. A longitudinal field investigation of gender differences in individual technology adoption decision-making processes. Organizational Behavior and Human Decision Processes, v. 83, n. 1, p. 33-60, 2000.

;____; Davis, G. B.; Davis, F. D. User acceptance of information technology: Toward a unified view. MIS Quarterly, p. 425-478, 2003.

.; Thong,J.Y.L; Xu, X. Consumer acceptance and use of information technology: extending the unified theory of acceptance and use of technology. MIS Quarterly, v. 36, n. 1, p. 157-178, 2012.

.; Zhang,X.; Sykes, T. A. "Doctors do too little technology": A longitudinal field study of an electronic healthcare system implementation. Information Systems Research, v. 22, n. 3, p. 523-546, 2011.

Wang, H. C.; Chiu, Y. F. Assessing e-learning 2.0 system success. Computers \& Education, v. 57, n. 2, p. 1790-1800, 2011.

Wang, A. Y.; Newlin, M. H. Predictors of web-student performance: The role of selfefficacy and reasons for taking an online class. Computers In Human Behavior, v. 18, n. 2, p. 151-163, 2002. 
WANG, Y.; Wu, M.; Wang, H. Investigating the determinants and age and gender differences in the acceptance of mobile learning. British Journal of Educational Technology, v. 40, n. 1, p. 92-118, 2009.

Williams, M. D.; Rana, N.; Dwivedi, Y.; Lal, B. Is UTAUT really used or just cited for the sake of it? A systematic review of citations of UTAUT's originating article. In: European Conference on Information Systems, 19., 2011. Proceedings... ECIS, 2011. Wixom, B. H.; Todn, P.A. A theoretical integration of user satisfaction and technology acceptance. Information Systems Research, v. 16, n. 1, p. 85-102, 2005.

Zhang, S.; Zhao, J.; TAN, W. Extending TAM for online learning systems: An intrinsic motivation perspective. Tsinghua Science Eఠ Technology, v. 13, n. 3, p. 312-317, 2008.

\section{SOBRE AS AUTORAS}

Vanessa Edy Dagnoni Mondini é doutora em ciências contábeis e administração pela Fundação Universidade Regional de Blumenau (FURB). Professora do Instituto Federal de Santa Catarina (IFSC). E-mail: profevanessamondini@gmail.com

Maria Jose Carvalho de Souza Domingues é doutora em engenharia de produção pela Universidade Federal de Santa Catarina (UFSC). Professora da Fundação Universidade Regional de Blumenau (FURB). E-mail:mjcsd2008@gmail.com 